\title{
CELEBRATING THE 55TH ANNIVERSARY OF THE JOURNAL OF CIVIL ENGINEERING AND MANAGEMENT: EDITORS' INTRODUCTION
}

\author{
Artūras KAKLAUSKAS ${ }^{*}$ Edmundas Kazimieras ZAVADSKAS, Ieva UBARTE் \\ Vilnius Gediminas Technical University, Sauletekio al. 11, LT-10223 Vilnius, Lithuania
}

Received 1 December 2021; accepted 21 December 2021

The Journal of Civil Engineering and Management (JCEM) has reached an important milestone this year, its 55th anniversary.

The JCEM, a Lithuanian journal dedicated to research in civil engineering that turns 55 in 2021 (Zavadskas, 2008) has its beginnings in the following journals:

- Selected papers on Mechanics, Lithuania (No. 1-33, 1967-1994; ISSN 0460-2242, Editor Prof. A. Čyras);

- Reinforced Concrete Structures (No. 1-16, 1967-1989, ISSN 0372-3070, Editor Prof. A. Kudzys);

- Building Materials and Structures (No. 1-9, 19711981, ISSN 0202-3210, Editor Prof. G. Marčiukaitis);

- Building Structures (No. 10-20, 1983-1995, ISSN 0208-2500, Editor Prof. G. Marčiukaitis);

- Construction Economics and Planning (No. 1-17, 1971-1990, ISSN 0202-3210, Editor Prof. K. Antanavičius);

- Construction Economics and Management (No. 18, 1993, ISSN 0208-2497, Editor Prof. K. Antanavičius);

- Construction Technology and Management (No. 1-7, 1984-1993, Editor Prof. E. K. Zavadskas);

- Repair and Reinforcement of Building Structures (No. 1-2, 1992 and 1995, Editor Prof. Z. Kamaitis).

In 1995, Vilnius Gediminas Technical University made the decision to combine all these journals into a single periodical research journal. Seven volumes of the new journal were published under the title Statyba (Civil Engineering). Each of the volumes consisted of 4-6 issues (vol. 1-7, 1995-2001, print ISSN 1392-1525, online ISSN 18223605, Editor Prof. E. K. Zavadskas) and included papers in multiple languages (Zavadskas, 2008).

In 2002, the journal was renamed to Journal of Civil Engineering and Management. Volumes 8-10, each consisting of 4 issues (in English) (print ISSN 1392-3730, online ISSN 1822-3605) were published between 2002 and 2004 (Zavadskas, 2008).
2008 marked a new stage in the development of the journal. That year the JCEM was indexed by Thomson Reuters Science Citation Index Expanded, Web of Science, and then the journal was granted the Impact Factor (IF) by the Thomson Reuter's Institute for Scientific Information (ISI) in 2010 (IF = 3.711). Since 2010, the JCEM has also been a CIB (International Council of Research and Innovation in Building and Construction) encouraged journal.

Now the JCEM journal is abstracted/indexed by the international databases:

- Clarivate Analytics databases: Science Citation Index Expanded (Web of Science Core Collection), Journal Citation Reports (SSCI edition);

- Dimensions;

- DOAJ (Directory of Open Access Journals);

- EBSCOhost: Academic Search Complete, Central \& Eastern European Academic Source, GreenFILE, Current Abstracts, TOC Premier;

- Elsevier Bibliographic Databases: SCOPUS, El Compendex (Engineering Village), INSPEC;

- Gale ${ }^{\circledast}$ Academic OneFile, InfoTrac Custom;

- Google Scholar;

- ICONDA (The International CONstruction DAtabase);

- Microsoft Academic;

- MyScienceWork;

- OpenAIRE2020 (deposit publications);

- ProQuest: ProQuest Central, Summon ${ }^{\mathrm{TM}}$, Ulrichsweb $^{\mathrm{TM}}$.

To analyse the way the Impact Factor (IF) has changed over time, Figure 1 presents the Clarivate Analytics IF data, and Figure 2 presents the Scopus CiteScore data. Both Clarivate Analytics and Scopus data show this indicator has been rising since 2014. The latest available ranking of the journal is as follows: Clarivate Analytics

*Corresponding author. E-mail: arturas.kaklauskas@vilniustech.lt 


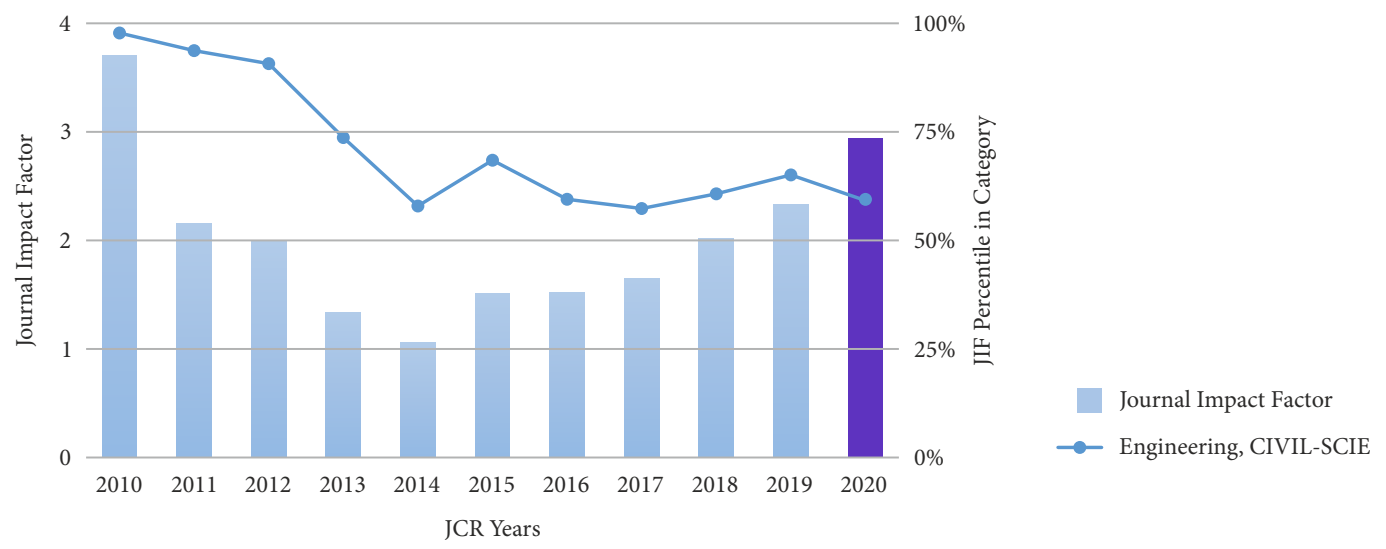

Figure 1. JCEM Impact factor by Clarivate Analytics (2021)

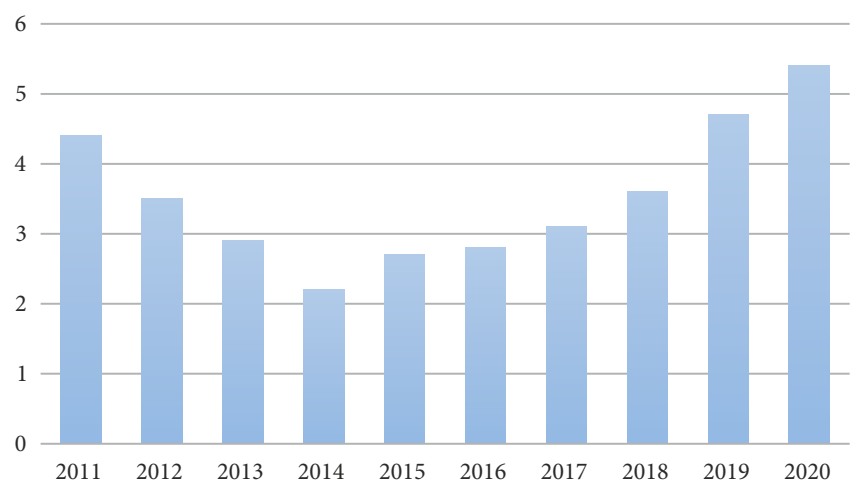

Figure 2. JCEM Impact factor by Scopus CiteScore (Elsevier, 2021)

Impact factor (2020), IF = 2.957; Scopus SCImago Journal Ranking (2020), SJR = 0.529; Scopus Source Normalized Impact per Paper (2020), SNIP = 1.401.

Based on the values of Impact Factors (IF) published by the Thomson Reuter's Institute for Scientific Information Web of Knowledge Journal Citation Reports, the journal is currently ranked 56th of 137 journals worldwide in the category of "Engineering, Civil" on the Clarivate Analytics Web of Science. Based on its worldwide impact in the category of "Engineering, Civil" on the Clarivate Analytics Web of Science, the JCEM has joined the journals in the second quartile (Q2).

The Journal of Civil Engineering and Management is a peer-reviewed journal that provides an international forum for the dissemination of the latest original research, achievements and developments. We publish for researchers, designers, users and manufacturers in the different fields of civil engineering and management. The journal publishes original articles that present new information and reviews. Our objective is to provide essential information and new ideas to help improve civil engineering competency, efficiency and productivity in world markets. The Journal of Civil Engineering and Management publishes articles in the following fields:

- All stages of the building life cycle;

- Building materials and structures;

- BIM;

- Smart built environment;

- Structural mechanics and physics;

- Geotechnical engineering;
- Road and bridge engineering;

- Urban engineering and economy;

- Construction technology, economy and management;

- Operational research;

- Digital twin;

- IoT;

- Robotics;

- Affective computing;

- Intelligent decision support systems;

- Information technologies in construction;

- Fire protection, thermal insulation and renovation of buildings;

- Labour safety in construction.

Figure 3 shows the highly cited keywords by the JCEM. The data suggest that the main highly cited keywords are construction, project, analysis, model, concrete, optimization, development and others.

The JCEM's highly cited keywords are also closely related to the top trends in construction and civil engineering (Figure 4). The JCEM publishes articles on robots and drones, building information modelling (BIM) and digital twins, smart building, smart cities, advanced materials, artificial intelligence, modular, offsite, and prefab construction, advance uses of GPS, etc.

In the period 1995-2007, 62 JCEM journal numbers were produced and 576 papers were published. The period between 2008 and 2021 saw 148 journal issues and one supplement (in 2013) published, counting over 1,000 papers. The international visibility of the journal and its im- 
pact on the scientific community has increased. Figure 5 shows the manuscripts submitted to the JCEM by region. The majority of these manuscripts are from Asian countries (74\%).

An analysis of the institutions with articles accepted in 2021 and their rankings in the QS World University Ranking (2021) and the Times Higher Education World University Ranking (2021) shows that $43 \%$ of the accepted articles are from institutions ranked in the TOP500 of the QS World University Ranking, while in the case of the Times Higher Education World University Ranking institutions from the TOP500 submitted $47 \%$ of the accepted articles (Figure 6).

Figure 7 shows the share of 2021 articles from Asian countries submitted by institutions ranked high on the QS World University Ranking (2021) and the Times Higher Education World University Ranking (2021). The same share of articles (46\%) are from institutions ranked in TOP500 both in the QS World University Ranking and the Times Higher Education World University Ranking. The share of institutions ranked in the TOP500-TOP1000, however, differs: $30 \%$ for the QS World University Ranking and 24\% for the Times Higher Education World University Ranking.
Figure 8 shows the share of 2021 articles from European countries submitted by institutions ranked high on the QS World University Ranking (2021) and the Times Higher Education World University Ranking (2021). Of the accepted articles, $27 \%$ were from institutions ranked in the TOP500 on the QS World University Ranking, and $37 \%$ from institutions ranked high on the Times Higher Education World University Ranking. The difference in the share of institutions ranked in the TOP500-TOP1000 is almost 2.4 times: $64 \%$ for the QS World University Ranking, and 27\% for the Times Higher Education World University Ranking.

Our Editorial Board have been great contributors to the success of the journal and we are grateful to them. Among the world-renowned members of our Editorial Board are the advisory editors Prof. Ajith Abraham, Prof. Hojjat Adeli, Prof. David Arditi, Prof. Juozas Augutis, Prof. Peter Barrett, Prof. Dinar Camotim, Prof. Alexandre Dolgui, Prof. Gintautas Dzemyda, Prof. Herbert A. Mang, Prof. Ronie Navon, Prof. Timon Rabczuk, Prof. Mattheos Santamouris, Prof. Miroslaw J. Skibniewski, Prof. Raimundas Šiaučiūnas, Prof. Zeshui Xu. We are proud of our journal's numerous and respectable members of the Editorial Board.

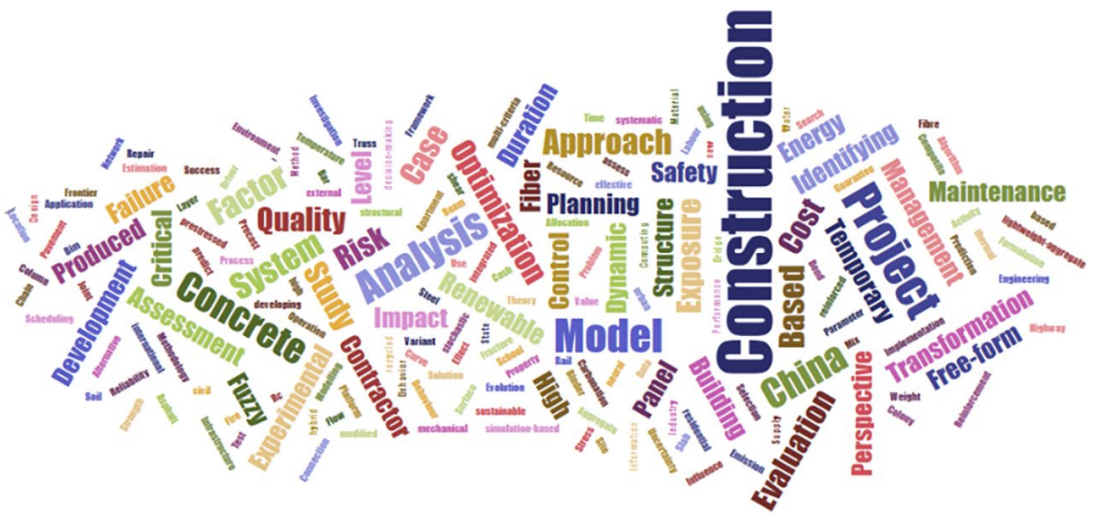

Figure 3. Highly cited keywords by JCEM (Academic Accelerator, 2021)

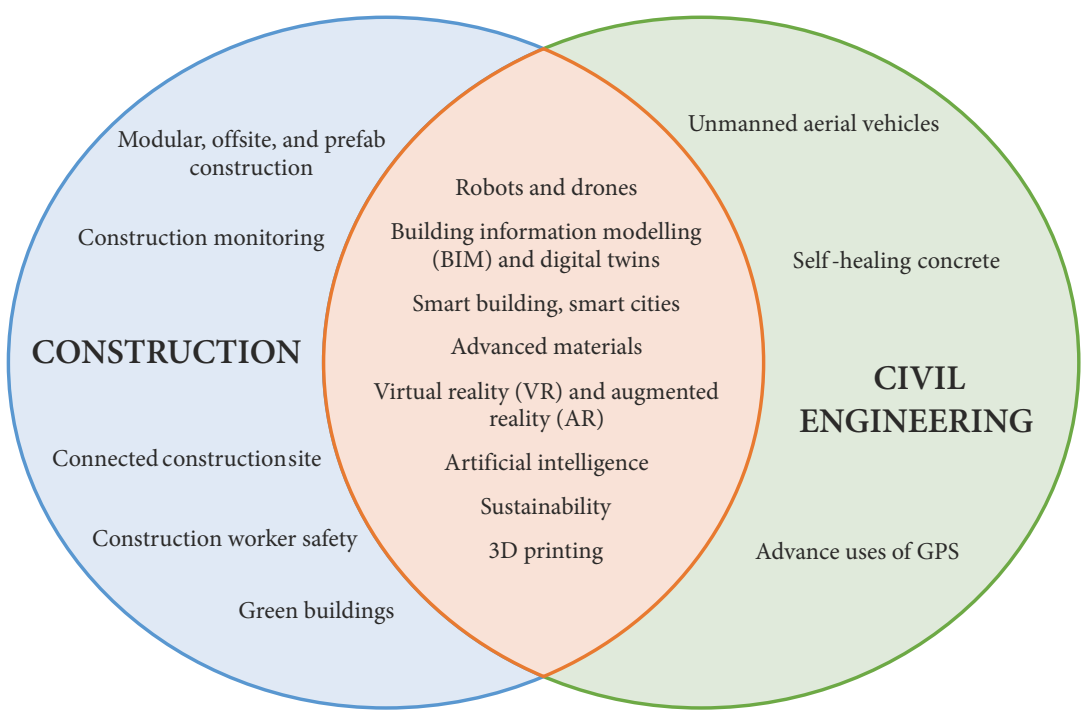

Figure 4. TOP trends topics in the Journal of Civil Engineering and Management 


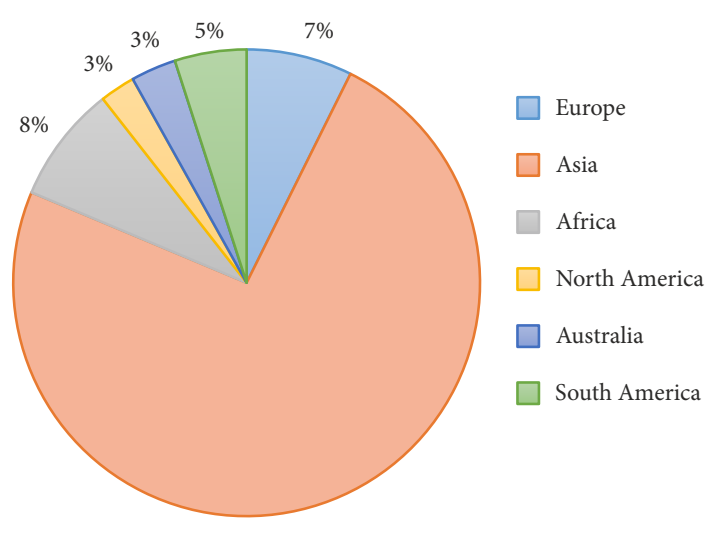

Figure 5. Manuscripts submitted by region
They include Dr. Mehrdad Arashpour, Dr. Vytenis Babrauskas, Dr. Rogerio Bairrao, Prof. György L. Balazs, Prof. WaiFah Chen, Prof. Min-Yuan Cheng, Prof. Dongping Fang, Prof. Meen-Wah Gui, Dr. M. Reza Hosseini, Prof. Zdenek Kala, Prof. Mieczyslaw Kaminski, Prof. Oleg Kaplinski, Dr. Kalle Kähkönen, Prof. Roode Liias, Prof. Hanbin Luo, Prof. Hartmut Pasternak, Prof. Friedel Peldschus, Prof. Mladen Radujkovic, Prof. Les Ruddock, Prof. Geoffrey Q. P. Shen, Dr. Alfred Strauss, Prof. Rimas Vaicaitis, Prof. Josef Vičan, Prof. Jirí Witzany, Dr. Chunlin Wu. JCEM Advisory Editors and our Editorial Board include 40 members from all over the world. Among the Advisory Editors and Editorial Board members 55\% are from Europe, 20\% from Asia, $17.5 \%$ from the USA and $7.5 \%$ from Australia.
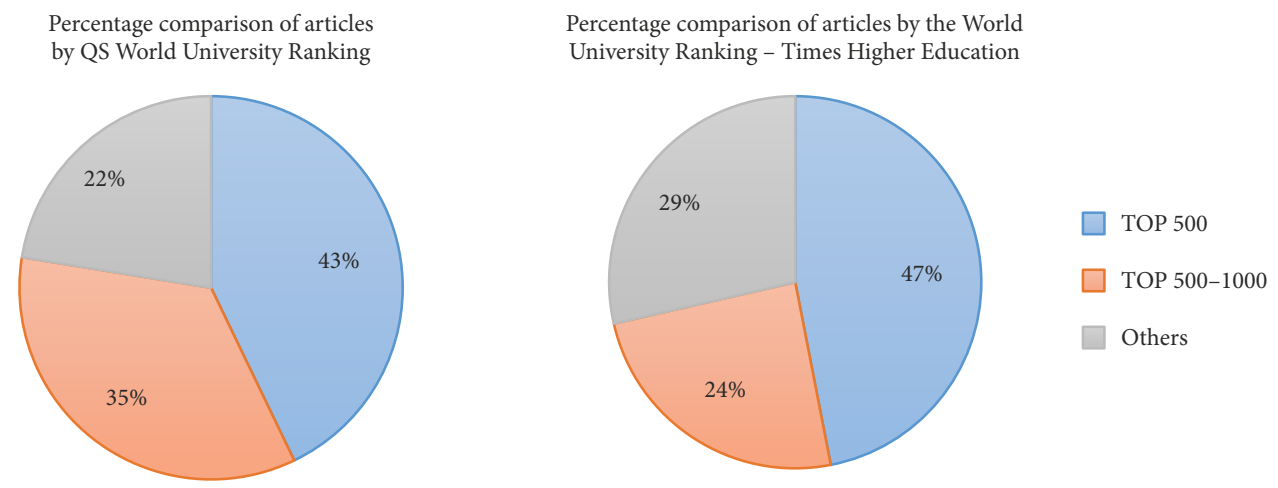

Figure 6. The share of articles from institutions ranked high on the QS World University Ranking (2021) and the Times Higher Education World University Ranking (2021)
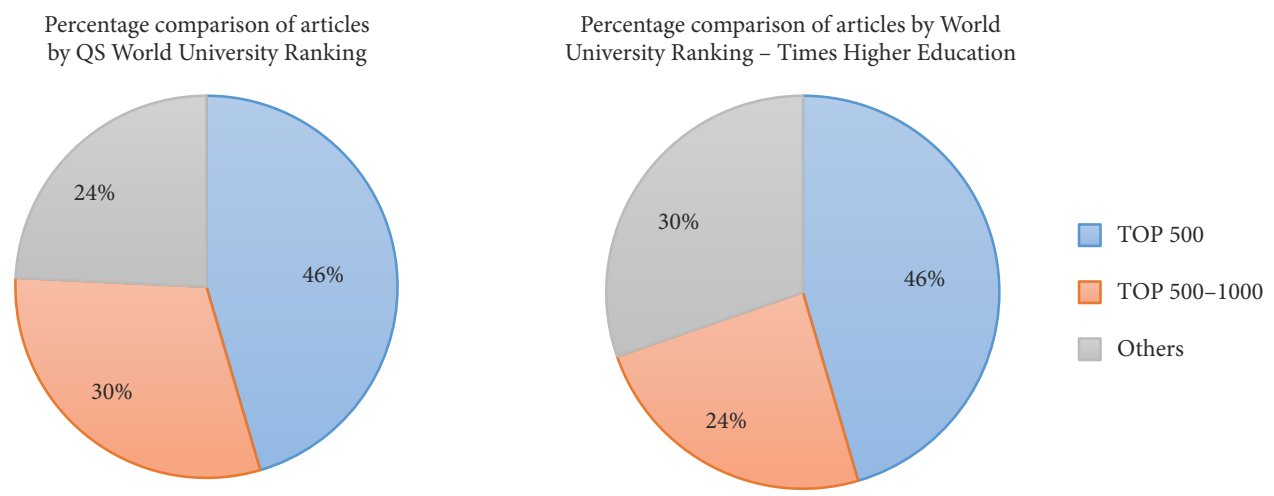

Figure 7. The share of articles from Asian institutions ranked high on the QS World University Ranking (2021) and the Times Higher Education World University Ranking (2021)
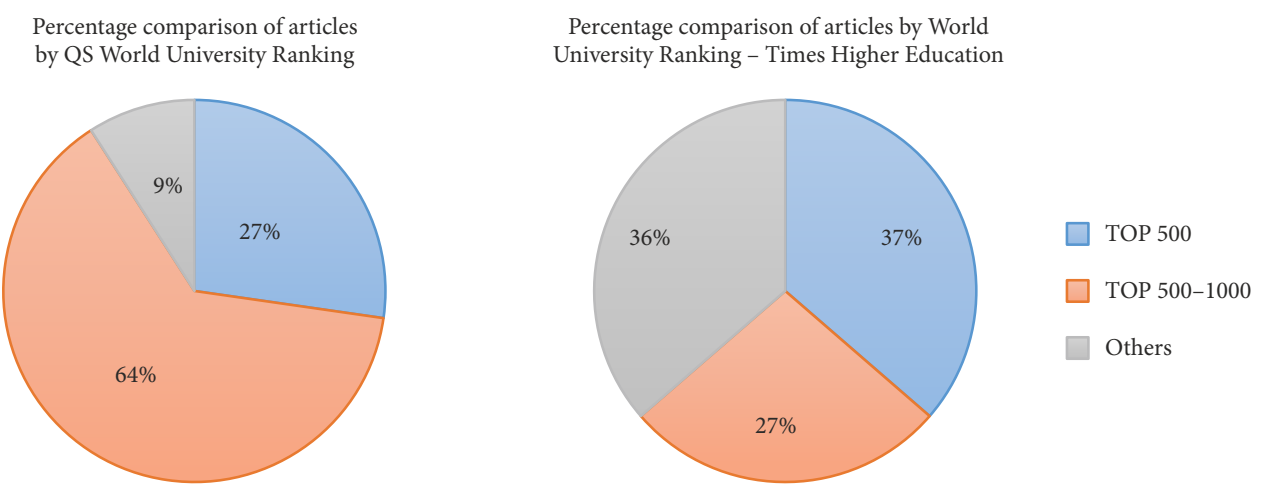

Figure 8. The share of articles from Europe institutions ranked high on the QS World University Ranking (2021) and the Times Higher Education World University Ranking (2021) 
Associate Editors help to make sure the journal maintains its scientific quality. They are research-active and reputable scholars: Prof. Gintaris Kaklauskas, Prof. Rimantas Kačianauskas. We also want to thank our Deputy Editor-in-Chief Prof. Jurgita Antuchevičienè and Managing Editor Dr. Laura Tupenaitè.

For their contribution to ensure an effective peer-review process, we also want to thank the reviewers of the journal. Many experts contribute to the quality of papers and the editors of the journal would like to express their sincere appreciation to all of them for the work they have done and continue doing.

Special thanks goes to the researchers who choose the Journal of Civil Engineering and Management as the venue to publish their research findings.

Finally, to all those who have contributed to the quality and success of the journal and its weight in the academic world, the editors once again would like to express their sincerest gratitude. We are truly grateful and look forward to our continued cooperation towards scientific success.

\section{References}

Academic Accelerator. (2021). Journal of Civil Engineering and Management. https://academic-accelerator.com/Journal-Profile/Journal-of-Civil-Engineering-and-Management

Clarivate Analytics. (2021). Journal citation reports. Journal of Civil Engineering and Management. https://jcr.clarivate. $\mathrm{com} /$ jcr-jp/journal-profile? app=jcr\&referrer=target $\% 3 \mathrm{Dhtt}$ ps:\%2F\%2Fjcr.clarivate.com\%2Fjcr-jp\%2Fjournal-profile $\%$ 3Fjournal\%3DJ\%2520CIV\%2520ENG\%2520MANAG\%26 year\%3D2020\&Init=Yes\&journal=J\%20CIV\%20ENG\%20 MANAG\&authCode=null\&year $=2020 \&$ SrcApp $=I C 2 L S$

Elsevier. (2021). Scopus. Source details. Journal of Civil Engineering and Management. https://www.scopus.com/sourceid/16255

QS World University Ranking. (2021). https://www.topuniversities.com/university-rankings/world-university-rankings/2021

Times Higher Education World University Ranking. (2021). https://www.timeshighereducation.com/content/world-university-rankings

Zavadskas, E. K. (2008). The fifth decade. Journal of Civil Engineering and Management, 14(1), 5-10.

https://doi.org/10.3846/1392-3730.2008.14.5-10 